\title{
Automobility-as-a-Service for Sustainable Cities
}

\author{
Yuri Saginov, Olga Saginova*
}

\author{
Plekhanov Russian University of Economics, Moscow, Russia \\ ${ }^{*}$ Corresponding author. Email: saginova.ov@rea.ru
}

\begin{abstract}
New technologies development and proliferation have been changing urban mobility patterns and preferences for more sustainable models minimizing negative ecological effects and providing more social space. Automobility as a service being part of Mobility-as-a-Service concept includes car-sharing services development. The paper analyses customers' motivation for car-sharing. Using online survey results of young active users of car-sharing services in Moscow, authors comment on usage situations, benefits sought, and choice parameters and draw conclusions relevant to car-sharing services in urban areas.
\end{abstract}

Keywords: mobility-as-a-Service, MaaS, automobility-as-a-Service, AaaS, car-sharing, digital platforms, motivation.

\section{INTRODUCTION}

Megacities around the world use urban mobility management tools to improve the efficiency of the urban transport system and reduce the negative environmental and socio-economic consequences of urban transport development [1]. Modern large cities are gradually abandoning the extensive development of transport through the construction of new roads and the increase in the number of cars and are switching to the "city for people" model. However, cars still dominate the city's transport system, providing speed, comfort, and flexibility of personal mobility.

The concept of automobility views cars, mostly gasoline-powered and driven by single drivers, not as isolated products but as a central element of a system of institutions, infrastructures, objects, behavioral models, ideologies, values, and people. Cars are the most important objects of individual consumption after housing, providing their owners/users with social status through such values as safety, career success, freedom, masculinity [2]. The automobile is the predominant global form of individual mobility, which determines how people perceive the opportunities and limitations of work, family life, leisure, and recreation [3]. The dominance of cars is ensured and explained by the freedom and flexibility that cars provide: the driver gets an opportunity to travel at any time in any direction along complex road systems that connect places of work, residence, and recreation areas. Free movement and interaction of pedestrians are giving way to tightly controlled driving. Urban landscapes were gradually changed to facilitate the movement of cars and hinder other forms of mobility [4]. The automotive infrastructure provides the possibility of maintaining social ties and implementing mobility over considerable distances [3]. The automotive industry separated jobs from places of residence, allowed the formation of separate residential and business districts, and modified urban centers and public spaces.

A culture of its own has been formed around cars, producing literary and artistic images and symbols $[5,6,7]$. The use of various material resources, space, and energy for the production of cars and the infrastructure necessary for them, as well as the scale of work to overcome the negative consequences of using cars on a global scale, forces us to look for alternative ways of organizing urban mobility [8].

Decisions on the modernization of the automotive industry are mainly linear in nature: reducing fuel consumption or improving the existing public transport [3], modernizing the road transport infrastructure. But the system of car ownership cannot be overcome by linear changes, a different model of mobility is required. The emergence of this new model is connected not only with the technical and economic transformations of various fuel systems and cars design, but also with political and social transformations, primarily affecting large urban agglomerations $[9,10]$.

Another way to move towards more sustainable urban mobility is changing the models of car ownership and 
usage. Car-sharing is turning a car into a service provided on demand when and where it is necessary and convenient for the user [11]. The development and implementation of alternative mobility opportunities due to intermodality, integrated public transport, improved conditions for cyclists and pedestrians make it possible to reduce the dominance of cars in the urban mobility models and minimize the negative impact of motor transport on the environment [10].

\section{MATERIALS AND METHODS}

In addition to changing the car itself and changing the models of car ownership, the perception of the mobility system is changing. The concept of Mobility-as-aService (MaaS) transforms the management of the city's transport system, changes the actors and stakeholders involved, affects the role and place of cars in economic and social life.

The MaaS concept, instead of owning and servicing a private car or using a combination of different types of public transport, offers a comprehensive mobility service that includes moving around the city and all related passenger services.

Within the framework of MaaS, automobility as a service (AaaS) is formed and implemented. It is a narrower concept, part of MaaS, and refers to services that provide personal movement by car. AaaS platforms offer users access to a vehicle without transferring ownership rights. The most radical view of the impact of AaaS on urban mobility [1] suggests a decrease in the use of personal cars by $18 \%$ from the current level.

To implement AaaS and manage it effectively, it is important to understand why city dwellers use carsharing, identify specific usage situations and car-sharing platform selection criteria. Previous research focusing on sustainability values among customers' motivations [12] and selection trends in automobility society [13] showed that sustainable development being an important factor in the formation of positive attitudes towards sharing, the economic benefits are a strong motivator for intentions to participate in car-sharing.

To identify the main motives for using car-sharing, clarify the situations of its use and parameters for selecting a car-sharing platform, an online survey of 500 users of car-sharing applications was conducted, including both car-owners and those without a private car. The survey was conducted on the basis of a questionnaire that included questions about the purposes of using car-sharing, situations of using the service, preferences in choosing a platform. Survey results were collected using Microsoft Forms.

\section{RESULTS AND DISCUSSION}

Fig. 1 shows the main goals of car-sharing depending on the frequency of its use by customers.

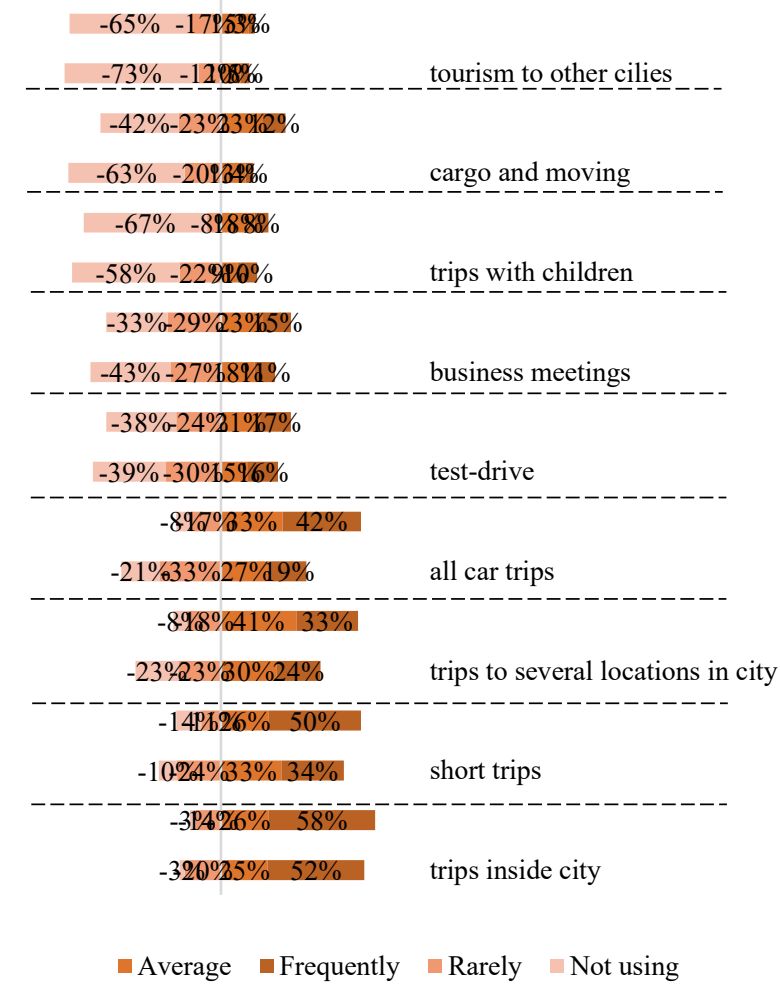

Figure 1 Goals of car-sharing.

It can be seen that for users with a private car, the main purpose of using car-sharing is to move around the city. More than half of users prefer the convenience of car comfort and flexibility. Goods transportation, trips with children and tourism are important goals for only 4$10 \%$ of users. For users without a private car, trips within the city are even more important - up to $58 \%$ of respondents chose this option. At the same time, for these users, the transportation of goods is a more important goal than for those with a private car. We can conclude that transportation of goods is an underestimated goal of car-sharing. Potentially, using a car-sharing service to transport some goods when shopping or changing the place of residence will be more in demand if there are car models for the purpose (a wagon or a minivan) offered by the car-sharing platform. 


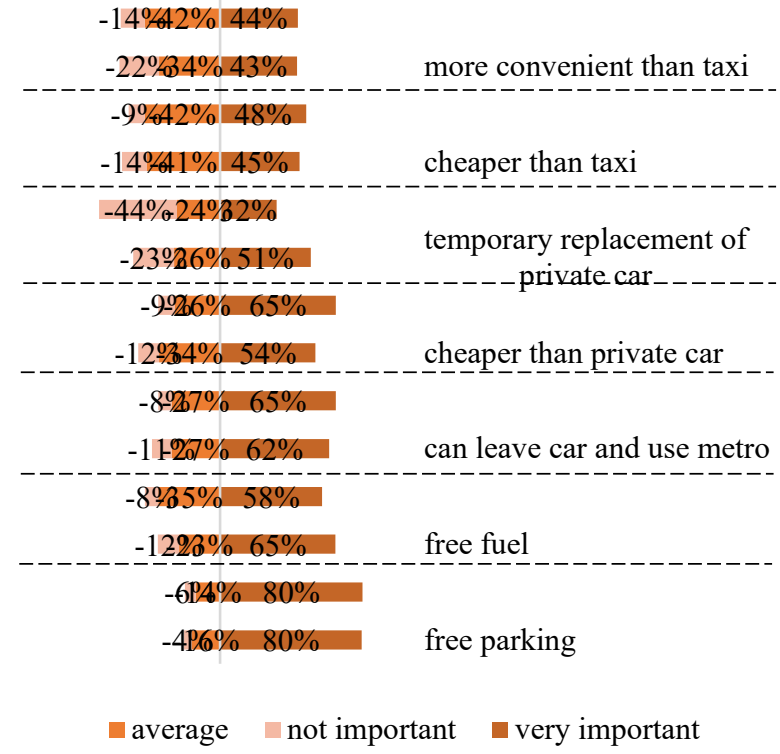

Figure 2 Motivations for using car-sharing.

The figure shows that free parking is the leading benefit sought (for $80 \%$ of users, both for car owners and those without a private car). The second most important motivator is the ability to leave the car and change to the subway (62-65\%), that is, the possibility of quickly changing the type of transport. The third most important (58-65\%) argument in favor of car-sharing is the ability not to refuel the car, that is, the convenience of using it as in public transport. In general, the economic advantages of car-sharing prevail. In the case of users without a private car, the comparison with the costs of car ownership is $10 \%$ more important than for car owners. We can conclude that the perception of car-sharing as a cheaper option of car ownership can further reduce the intention to buy the first private car.

Answering questions and the choice of car model respondents indicated the comfort of use and the most important criteria: access time to the car (69-71\%), fuel sufficiency $(63-73 \%)$, and cleanliness of the vehicle and interior (54-52\%). The price was also mentioned among the most important criteria (64-67\%), but judging by the results, it is not the main criterion. This allows us to conclude about the potential elasticity of demand with an increase in cost and compliance with the criteria of the comfort of use. It is worth noting that the criterion of the car class is more important for users without a private car (31\%) compared to car owners (24\%).

Criteria for choosing a car-sharing platform are shown in Fig. 3.

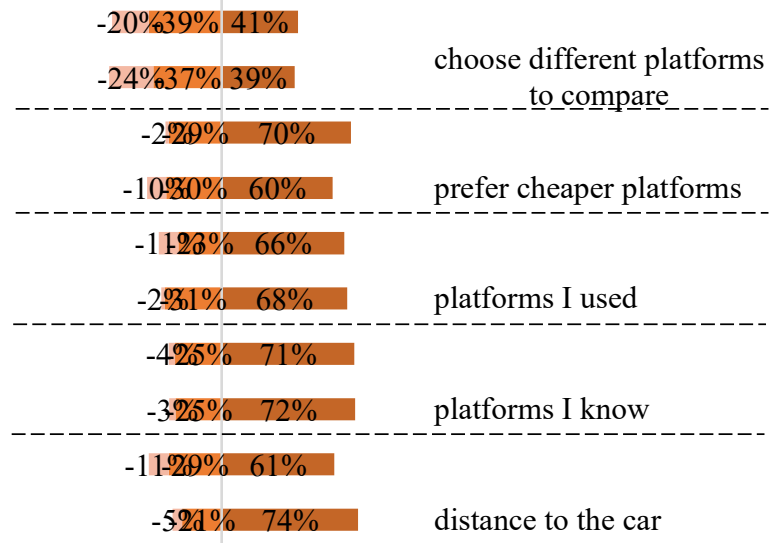

घavergare $\square$ not important $\square$ very important

Figure 3 Platform selection criteria.

Most of the respondents (66-72\%), both with and without a private car, prefer to choose a well-known or previously used platform/application. The proximity of the car is more important for users with a private car (74\%) compared to users without it (61\%). The economic cost is more important for users without a private car $(70 \%)$, compared to car owners $(60 \%)$. It is worth noting that the choice of a different (unfamiliar) platform is not an important criterion (39-41\%) compared to other criteria, which indicates a positive experience of using the leading platforms and user loyalty to these platforms.

\section{CONCLUSION}

The car in the system of urban mobility has ceased to be just a product (hardware), it has become part of a service. The perception of the product (car) has changed and continues to change - from more emotional to more pragmatic as a means of mobility, there is no status of car ownership, especially among young people.

When using AaaS, there is no clear preference for the model and brand of the car, there are distinctions by car class (based on the pragmatic perception of comfort level).

The existing car-sharing systems do not consider situations of using these services for goods transportation, so the fleet of car-sharing vehicles can be expanded to include car models for this type of use.

The role of government or city administration support for car-sharing services is important because the provision of parking spaces in convenient city venues and low or no parking fees are important motivations for carsharing users. 


\section{AUTHORS' CONTRIBUTIONS}

Both authors developed ideas and collected data for this article, were involved in drafting and editing the text of the paper.

\section{REFERENCES}

[1] J. Airbib, T.Seba, Rethinking transportation 20202030 The Disruption of Transportation and the Collapse of the Internal-Combustion Vehicle and Oil Industries, https://static1.squarespace.com/, 2018.

[2] D. Miller, Car Cultures. Routledge, 2001. ISBN 9781859734070.

[3] J. Urry, The 'System' of Automobility. Theory. Culture and Society, 21(4-5) (2004) pp. 25-39.

[4] P. Freund, The Ecology of the Automobile. Black Rose Books, Montreal and New York, 1993.

[5] B. Bachmair, From the Motor-car to Television: Cultural-historical Arguments on the Meaning of Mobility for Communication, Media. Culture \& Society, 199(113) pp. 521-33.

[6] R. Eyerman, O. Löfgren, Romancing the Road: Road Movies and Images of Mobility. Theory, Culture \& Society, 12(1) (1995) pp. 53-79.

[7] P. Graves-Brown, From Highway to Superhighway: The Sustainability, Symbolism and Situated Practices of Car Culture. Social Analysis, 41 (1997) pp. 64-75.

[8] J. Adams, The Social Implications of Hypermobility, OECD Project on Environmentally Sustainable Transport, UCL, 1999.

[9] F. Geels, R. Kemp, G. Dudley, G. Lyons, Automobility in transition? Routledge, A SocioTechnical Analysis of Sustainable Transport, 2012.

[10] G. Vigar, The Politics of Mobility. Routledge, 2001.

[11] K.N. Ireeva, D. Zavyalov, O. Saginova, N. Zavyalova, Y. Saginov, User interest in car sharing as an indicator of sustainable urban agglomeration development, In: E3S Web of Conferences, 244 p. 08025 .

DOI: https://doi.org/10.1051/e3sconf/202124408025.

[12] O.V. Saginova, N.S. Kireeva, Yu.L. Saginov, D.V. Zavyalov, Dataset on the questionnaire-based survey of sharing services users' motivation Data in Brief., 33 (2020) p. 106502.

[13] M. Mohsen, Sharing or owning autonomous vehicles? Comprehending the role of ideology in the adoption of autonomous vehicles in the society of automobility. Transportation Research
Interdisciplinary Perspectives 9(2) (2021) p. 100294. DOI: 